\title{
Australian mosquito assemblages vary between ground and sub-canopy habitats
}

\author{
Boni F. Sebayang ${ }^{1 *}$, Tanya L. Russell ${ }^{1}$, Kyran M. Staunton ${ }^{1}$, Michael Townsend ${ }^{1}$, Christopher Paton', \\ Tovi Lehmann ${ }^{2}$ and Thomas R. Burkot ${ }^{1}$
}

\begin{abstract}
Background: The surveillance and control of mosquito-borne diseases is dependent upon understanding the bionomics and distribution of the vectors. Most studies of mosquito assemblages describe species abundance, richness and composition close to the ground defined often by only one sampling method. In this study, we assessed Australian mosquito species near the ground and in the sub-canopy using two traps baited with a variety of lures.

Methods: Mosquitoes were sampled using a $4 \times 4$ Latin square design at the Cattana Wetlands, Australia from February to April 2020, using passive box traps with octenol and carbon dioxide and three variations of a sticky net trap (unbaited, and baited with octenol or octenol and carbon dioxide). The traps were deployed at two different heights: ground level ( $\leq 1 \mathrm{~m}$ above the ground) and sub-canopy level ( $6 \mathrm{~m}$ above the ground).

Results: In total, 27 mosquito species were identified across the ground and sub-canopy levels from the different traps. The abundance of mosquitoes at the ground level was twofold greater than at the sub-canopy level. While the species richness at ground and sub-canopy levels was not significantly different, species abundance varied by the collection height.

Conclusions: The composition of mosquito population assemblages was correlated with the trap types and heights at which they were deployed. Coquillettidia species, which prefer feeding on birds, were mainly found in the subcanopy whereas Anopheles farauti, Aedes vigilax and Mansonia uniformis, which have a preference for feeding on large mammals, were predominantly found near the ground. In addition to trap height, environmental factors and mosquito bionomic characteristics (e.g. larval habitat, resting behaviour and host blood preferences) may explain the vertical distribution of mosquitoes. This information is useful to better understand how vectors may acquire and transmit pathogens to hosts living at different heights.
\end{abstract}

Keywords: Vertical distribution, Australian mosquitoes, Mosquito traps, Height

\section{Background}

Mosquitoes are competent vectors for arboviruses, helminths and protozoans that can affect animal and human health [1]. Nearly half of the human population is at risk of mosquito-borne diseases [1]. The geographic risk of exposure to mosquito-borne diseases is increasing as

\footnotetext{
*Correspondence: boni.sebayang@my.jcu.edu.au

${ }^{1}$ Australian Institute of Tropical Health and Medicine (AITHM), James Cook University, Cairns, QLD 4878, Australia

Full list of author information is available at the end of the article
}

vector distributions change, driven by a variety of factors, including climate change and the movement of wildlife, humans and commercial goods $[1,2]$. Additionally, the risk of exposure to biting mosquitoes can change due to behavioural plasticity, frequently in response to mosquito control efforts $[3,4]$.

Vector control is the most effective method to control the transmission of mosquito-borne diseases $[1,4,5]$. Effective vector control requires a detailed understanding of the bionomics and distribution of mosquitos [68]. Mosquito distributions are highly heterogeneous, original author(s) and the source, provide a link to the Creative Commons licence, and indicate if changes were made. The images or other third party material in this article are included in the article's Creative Commons licence, unless indicated otherwise in a credit line to the material. If material is not included in the article's Creative Commons licence and your intended use is not permitted by statutory regulation or exceeds the permitted use, you will need to obtain permission directly from the copyright holder. To view a copy of this licence, visit http://creativecommons.org/licenses/by/4.0/. The Creative Commons Public Domain Dedication waiver (http://creativeco mmons.org/publicdomain/zero/1.0/) applies to the data made available in this article, unless otherwise stated in a credit line to the data. 
and this heterogeneity needs to be considered when designing mosquito sampling strategies [9, 10]. Gillies and Wilkes [11] categorised mosquito species as: (i) mosquitoes that only fly near the ground $(<1 \mathrm{~m})$; (ii) mosquitoes that fly predominantly within $2-4 \mathrm{~m}$ of the ground; and (iii) mosquitoes that fly $\geq 6 \mathrm{~m}$ above the ground, with flight patterns hypothesised to be associated with the vertical distribution of a mosquito's preferred blood meal hosts [11]. Clearly, the height at which a mosquito trap is placed can influence the catch rates; however, most studies only focus on quantifying the abundance and horizontal distribution of mosquitoes at the ground level [12, 13]. Recently, the extent of aerial distribution of mosquitoes was highlighted by studies of anophelines in Africa at heights up to $290 \mathrm{~m}$ [14], thereby demonstrating how important altitude can be to mosquito bionomics, distributions and dispersal.

Moreover, vegetation structure and meteorological conditions can influence mosquito movement and their distributions $[15,16]$. The visual environment can create a physical barrier that influences the behaviour patterns of mosquito species [16]. Light intensity also impacts mosquito blood-seeking and resting behaviours and thus the distribution of mosquitoes, particularly those that are active for the entire day [15].

Mosquito assemblages can be described by their species' abundance, richness and composition (the latter two being measures of diversity) [11, 17, 18]. Abundance or density relates to the direct count of the individuals of a species per unit of space, and richness is the count of the number of different species present, with assemblage composition reflecting the relative abundance of each species sampled [19]. Understanding these three components of mosquito populations is a fundamental step towards effectively controlling mosquito populations and any pathogens that they might transmit $[13,14,20]$.

Defining mosquito abundance, richness and composition requires appropriate sampling methods [21, 22] as each sampling method has unique attributes and biases $[10,21,23]$. For example, among the commonly used methods for sampling adult mosquitoes, human landing catches (HLC) target anthropophagic species, CDC-light traps capture nocturnally active mosquitoes while barrier screens target resting behaviours of mosquitoes of all physiological states, including host-seeking mosquitoes [23-26]. Hence, studies of mosquito distributions require multiple sampling methods to comprehensively sample all species of all physiological states. In the present study, we assessed Australian mosquito species at two heights using two traps baited with a variety of lures to define species abundance, species richness and assemblage composition to define mosquito species aggregations.

\section{Methods}

\section{Study site and study period}

The study was conducted in the Cattana Wetlands $\left(16^{\circ} 49^{\prime} 50.027^{\prime \prime} \mathrm{S}, 145^{\circ} 42^{\prime} 18.611^{\prime \prime} \mathrm{E}\right)$, Queensland, Australia between February and April 2020 under a permit issued by the Cairns Regional Council. This 80 -ha environmental park encompasses palustrine and riverine ecosystems with rainforest trees, including Archontophoenix alexandraei, Melaleuca spp., Corymbia spp., Ficus spp. and Pandanus spp., as well as wetland grasses and sedges characterised by Para Grass and Navua Sedge [27]. The Cattana Wetlands provides habitat for a range of ground and arboreal amphibians, reptiles, mammals and birdlife.

\section{Sample stations}

Mosquitoes were sampled concurrently within the Cattana Wetlands at each of four stations using traps set at two heights: ground level (within $1 \mathrm{~m}$ of the ground) and in the sub-canopy (6 $\mathrm{m}$ above the ground). The sub-canopy layer at the stations is characterised by juvenile trees, shrubs and herbs growing under the main canopy layer [28]. The sub-canopy normally is defined as the layer from $5 \mathrm{~m}$ above the ground and extending to the first branches of the main canopy [28]. The minimum distance between sampling stations was $100 \mathrm{~m}$ to minimise interactions between traps at different stations. Each sampling station had a tree with a branch at least $6 \mathrm{~m}$ above the ground that was capable of supporting a weight $>5 \mathrm{~kg}$ (combined maximum weight of a mosquito trap with lure), was accessible by walking and was not exposed to direct sunlight. Wind speed, temperature and humidity were recorded using a weather meter (Kestrel AU, East Melbourne, VIC, Australia) at each height level. Individuals servicing traps applied DEET-based mosquito repellent before visiting trapping stations (Aerogard; Reckitt Benckiser, Sydney, Australia).

\section{Mosquito traps}

Two types of traps were used for sampling mosquitoes: the sticky net trap [14] and the passive box trap (POD) $[29,30]$. The PODs were constructed of clear $37 \times 29 \times$ 27-cm (20 L) polyethylene boxes, with mosquitoes entering the trap through an inverted mesh funnel with an external opening of $616 \mathrm{~cm}^{2}$, tapering to $78.5 \mathrm{~cm}^{2}$ inside the trap (Fig. 1). The PODs were baited with 1-octen3-ol (octenol) (Mozzie Attract; The Kelly Company Ply Ltd., Seven Hills, Australia) and $1.5 \mathrm{~kg}$ of dry ice in an insulated cooler from which carbon dioxide $\left(\mathrm{CO}_{2}\right)$ was emitted. The sticky net traps (Fig. 2) were $40 \times 60-\mathrm{cm}$ rectangular frames constructed with 25-mm-diameter PVC pipe on which black polyester netting (36 holes per $\mathrm{cm}^{2}$ mesh) with a film of $60 \mathrm{~g} / \mathrm{m}^{2}$ adhesive $\left(\mathrm{TAD}^{\mathrm{TM}}\right.$ All weather; Trece Adhesive Division ${ }^{\mathrm{TM}}$, Grand Rapids, MI, 


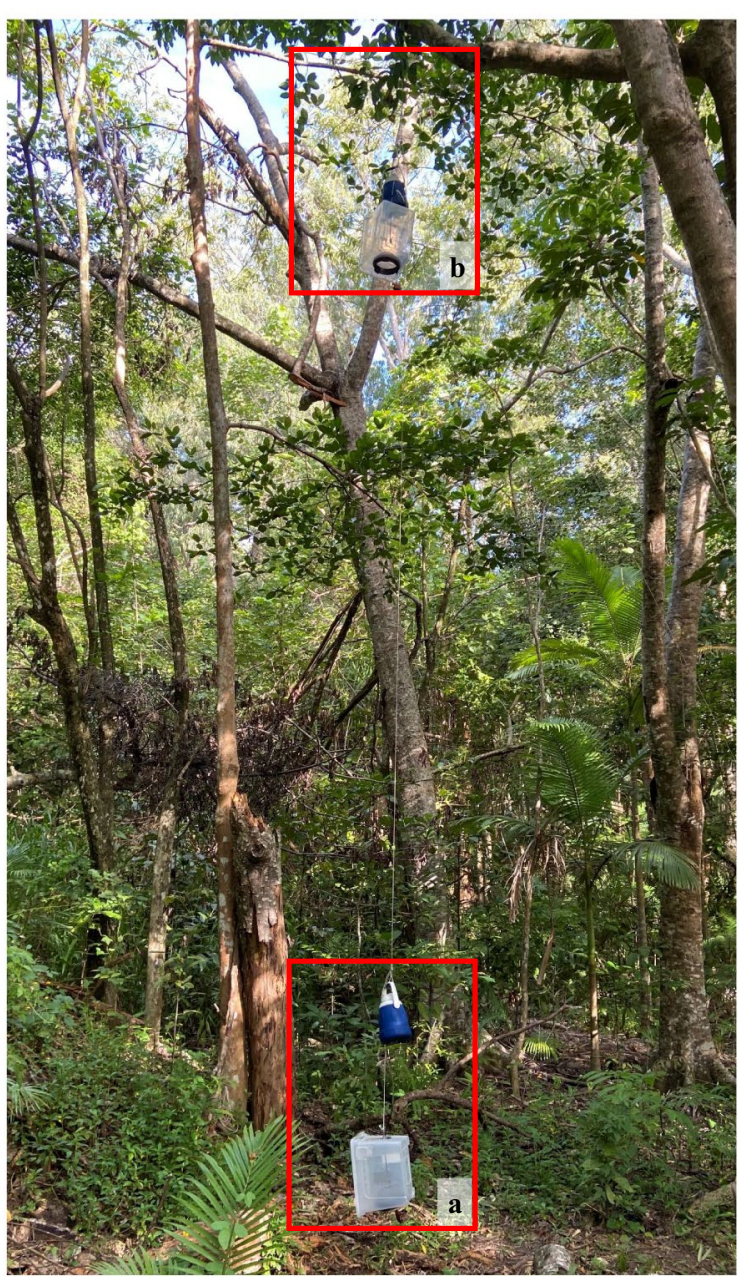

Fig. 1 Passive box trap with octenol and dry ice (POD) as lures at ground level $(<1 \mathrm{~m})$ (a) and sub-canopy level $(>6 \mathrm{~m})$ (b)

USA) was applied. Sticky net traps were used either without any lures (S), baited with octenol (SO) or with a combination of octenol and $1.5 \mathrm{~kg}$ of dry ice (SOD). Whereas SO and SOD traps consisted of netting with adhesive film on a single frame, the unbaited $S$ traps were composed of five net frames with adhesive as a low catch rate was anticipated. Hence, four trap types were compared: the POD, S, SO and SOD.

\section{Experimental design}

Mosquito sampling with the four trap types occurred over 16 nights using a $4 \times 4$ Latin square design [31]. On any given night, at each station, one of the trap types was deployed in pairs, concurrently at ground and sub-canopy levels. The trap types were allocated randomly across the four sampling stations over 4 sequential nights (full rotation) to minimise location

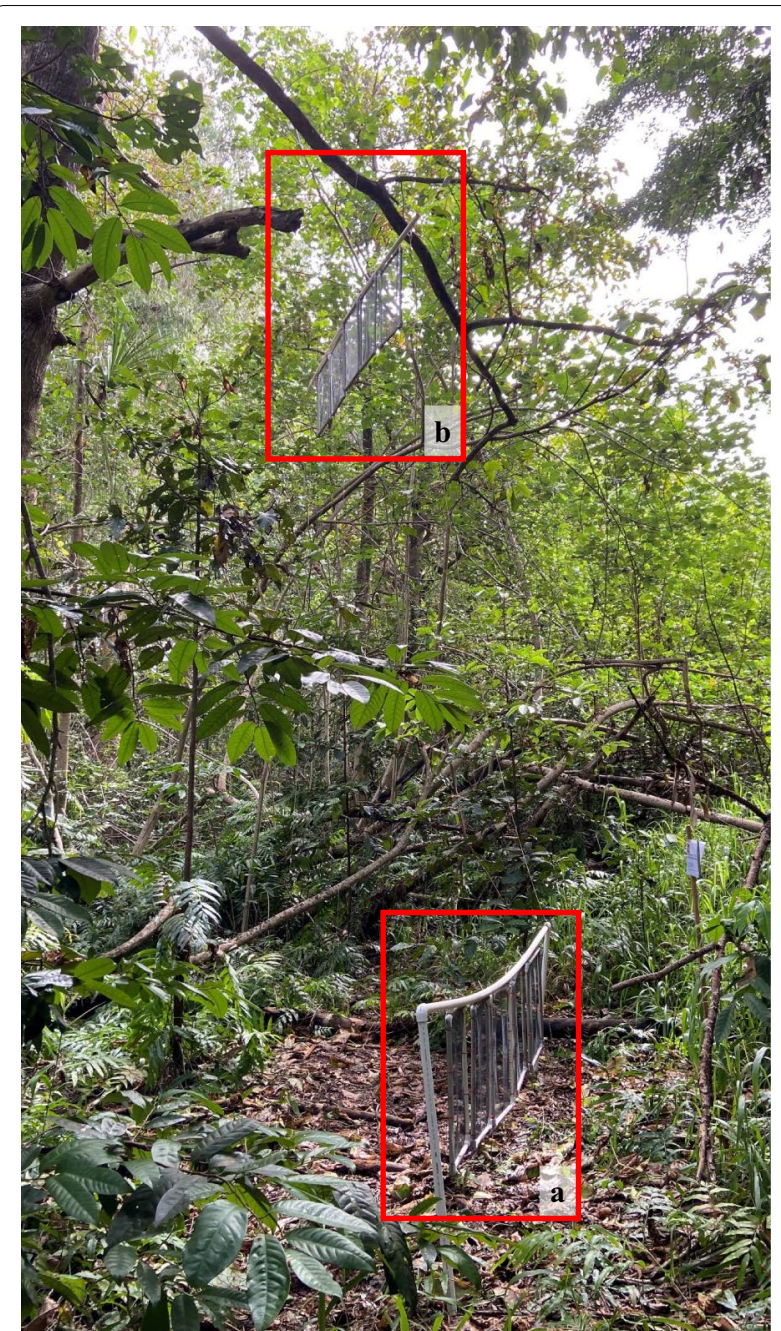

Fig. 2 Sticky net traps without any lure (S) at ground level $(<1 \mathrm{~m})(\mathbf{a})$ and at sub-canopy level $(>6 \mathrm{~m})(\mathbf{b})$

bias. Mosquito sampling occurred between 16:00 and 08:00 hours. Traps were removed from the sampling stations every morning and transferred to the laboratory. Mosquitoes were removed from sticky net traps with fine forceps and immediately identified. Other insects were removed to "clean" the sticky net traps between each sampling effort. Mosquitoes captured by the POD were killed by placing them in a freezer for at least $1 \mathrm{~h}$ and then transferred to an airtight container at $-20{ }^{\circ} \mathrm{C}$ until identified. All mosquitoes were identified morphologically under a stereomicroscope (Olympus, Tokyo, Japan) to species and sex [32], and the abdominal status of females classified as unfed, bloodfed or gravid. The numbers of mosquitoes, by species, sex and abdominal status, from each trap, height and station were recorded. 


\section{Statistical analysis}

The number of adult mosquitoes captured during each sampling effort was electronically recorded using the Ona platform (https://ona.io), and the final dataset was exported to MS Excel (Microsoft Corp., Redmond, WA, USA) for statistical analyses with the $\mathrm{R}$ statistical environment (ver. 4.0.3; https://www.r-project.org). The outcomes examined were mosquito abundance, richness and assemblage composition. Abundance was the number of specimens; richness was a count of the number of different species; and assemblage composition was the number of mosquitoes and their relative numbers. Trap 'type' and 'height' and the interaction of both parameters were used to estimate mosquito abundance and richness in separate generalised linear models (GLMs). Initial models were run using Poisson distributions, but there were overdispersed and therefore rerun using negative binomial distributions with log-link functions to account for overdispersion. An ordination of the entire female mosquito assemblage sampled was displayed graphically using non-metric multidimensional scaling (NMDS) run with the vegan package (ver. 2.5-7) [33]. In addition, the tidyverse package (ver. 1.3.0) was used to display the accumulated species richness curves of mosquitoes against the 16 nights sampling effort of each trap type by height. Lastly, the influence of both trap type and height, as well as their interaction, on assemblage composition and the individual species were also analysed using the likelihood ratio test (LRTs) in the mvabund package (ver. 3.6.11) [34]. LRTs compared mosquito composition, either including or not including the interaction between trap types and height.

\section{Results}

\section{Mosquitoes captured}

A total of 46,474 mosquitoes (137 males and 46,337 females, 12 which were engorged, but not any gravid mosquitoes) were captured over the 16 nights of collecting, from nine genera [Culex $(n=18,889)$, Aedes $(n=14,117)$, Verralina $(n=7,233)$, Anopheles $(n=4581)$, Coquillettidia ( $n=825)$, Mansonia $(n=640)$, Tripteriodes $(n=70)$, Lutzia $(n=16)$ and Uranotaenia $(n=1)]$. Of these 46,474 mosquitoes, 102 specimens were not identifiable due to their poor condition (Table 1).

A total of 27 mosquito species were identified (Table 2), of which the seven most abundant species, comprising 92.3\% of all specimens captured, were: Culex annulirostris $(n=13,787 ; 30.1 \%)$, Aedes vigilax ( $n=7986$; $17.5 \%)$, Aedes kochi $(n=5312 ; 11.6 \%)$, Anopheles farauti $(\mathrm{n}=4577 ; 10.0 \%)$. Verrallina funerea $(n=4196 ; 9.2 \%)$, Culex sitiens $(n=4054 ; 8.9 \%)$ and Verrallina carmenti
Table 1 Total numbers of male and female mosquitoes captured in Cattana Wetlands, Australia, by genera

\begin{tabular}{lllll}
\hline Genera & Male $(n)$ & \multicolumn{2}{l}{ Female $(n)$} & Total $(n)$ \\
\cline { 3 - 4 } & & Fed & Unfed & \\
\hline Aedes & 20 & 3 & 14,094 & 14,117 \\
Anopheles & 0 & 0 & 4581 & 4581 \\
Coquillettidia & 0 & 0 & 825 & 825 \\
Culex & 43 & 5 & 18,841 & 18,889 \\
Lutzia & 0 & 0 & 16 & 16 \\
Mansonia & 0 & 0 & 640 & 640 \\
Tripteroides & 0 & 0 & 70 & 70 \\
Uranotaenia & 0 & 0 & 1 & 1 \\
Verrallina & 0 & 4 & 7229 & 7233 \\
Unidentified & 74 & 0 & 28 & 102 \\
Total & 137 & 12 & 46,325 & 46,474 \\
\hline
\end{tabular}

( $n=2300 ; 5.0 \%)$. Twenty species comprised the remaining $7.7 \%(n=3532)$ of mosquitoes sampled.

Most female mosquitoes were collected from PODs (total $=44,905,96.9 \%$ ) and only $3.1 \%$ were collected from the variants of sticky net traps (Table 2). This trend was consistent for the seven main mosquito species, with the exception of $C x$. annulirostris and $C x$. sitiens. The PODs had a higher efficiency, capturing more species (total of 26 species) than the variants of sticky net traps, which only captured 12 out of 27 species (Table 3). Uranotaenia albescens $(n=1)$ was caught only in the unbaited sticky net trap (trap $S$ ) and not by the POD.

The average ( \pm standard deviation) nighttime temperatures at the ground and sub-canopy levels were $26.3 \pm 0.07{ }^{\circ} \mathrm{C}$ and $25.4 \pm 0.07{ }^{\circ} \mathrm{C}$, respectively, with an average humidity of $85.2 \pm 0.17$ and $82.0 \pm 0.30 \%$, respectively. The average wind speed at ground level was $0.26 \pm 0.03 \mathrm{mph}$, and $0.32 \pm 0.04 \mathrm{mph}$ at sub-canopy level. Limited variability in the temperature, relative humidity and wind speed throughout the study precluded analysis for associations with trap catches and, consequently, these parameters aware not included in the statistical models.

\section{Influence of trap and height on mosquito relative abundance and species richness}

Mosquito abundance was significantly influenced by trap type (GLM, $P<0.001$; Table 4; Fig. 3a). PODs caught significantly $(1391.7 \pm 161.8$; mean $\pm S D)$ more mosquitoes than any sticky net trap. Among the sticky net traps, significantly more mosquitoes were captured when octenol and dry ice were used $(36.6 \pm 6.9)$ than with either the 
Table 2 Total numbers of identified female mosquitoes captured in Cattana Wetlands, Australia, by species

\begin{tabular}{|c|c|c|c|c|c|c|c|c|c|}
\hline \multirow{2}{*}{$\begin{array}{l}\text { Trap types } \\
\text { Mosquito species }\end{array}$} & \multicolumn{2}{|l|}{$\operatorname{POD}(n)$} & \multicolumn{2}{|l|}{$\operatorname{SOD}(n)$} & \multicolumn{2}{|l|}{$\mathrm{SO}(n)$} & \multicolumn{2}{|l|}{$S(n)$} & \multirow[t]{2}{*}{ Total } \\
\hline & Ground level & Sub-canopy level & Ground level & $\begin{array}{l}\text { Sub- } \\
\text { canopy } \\
\text { level }\end{array}$ & Ground level & $\begin{array}{l}\text { Sub- } \\
\text { canopy } \\
\text { level }\end{array}$ & Ground level & $\begin{array}{l}\text { Sub- } \\
\text { canopy } \\
\text { level }\end{array}$ & \\
\hline Aedes alternans (Westwood) & 24 & 60 & 0 & 0 & 0 & 0 & 0 & 0 & 84 \\
\hline Aedes kochi (Donitz) & 2355 & 2261 & 436 & 254 & 2 & 2 & 2 & 0 & 5312 \\
\hline Aedes lineatopennis (Ludlow) & 16 & 3 & 0 & 0 & 0 & 0 & 0 & 0 & 19 \\
\hline Aedes notoscriptus (Skuse) & 233 & 162 & 6 & 8 & 0 & 1 & 0 & 1 & 411 \\
\hline Aedes palmarum (Edwards) & 30 & 11 & 0 & 3 & 0 & 0 & 0 & 0 & 44 \\
\hline Aedes tremulus (Theobald) & 38 & 25 & 0 & 1 & 0 & 0 & 0 & 0 & 64 \\
\hline Aedes vigilax (Skuse) & 5962 & 1933 & 57 & 23 & 8 & 1 & 2 & 0 & 7986 \\
\hline Aedes vittiger (Skuse) & 0 & 1 & 0 & 0 & 0 & 0 & 0 & 0 & 1 \\
\hline Anopheles amicatus (Edwards) & 1 & 0 & 0 & 0 & 0 & 0 & 0 & 0 & 1 \\
\hline Anopheles brancroftii (Giles) & 3 & 0 & 0 & 0 & 0 & 0 & 0 & 0 & 3 \\
\hline Anopheles farauti (Laveran) & 3963 & 266 & 292 & 55 & 1 & 0 & 0 & 0 & 4577 \\
\hline $\begin{array}{l}\text { Coquillettidia sp. near crassipes } \\
\text { (Marks) }\end{array}$ & 101 & 545 & 0 & 0 & 0 & 0 & 0 & 0 & 646 \\
\hline $\begin{array}{l}\text { Coquillettidia xanthogaster } \\
\text { (Edwards) }\end{array}$ & 29 & 150 & 0 & 0 & 0 & 0 & 0 & 0 & 179 \\
\hline Culex annulirostris (Skus) & 8117 & 5663 & 0 & 7 & 0 & 0 & 0 & 0 & 13,787 \\
\hline Culex cubiculli (Marks) & 0 & 9 & 0 & 0 & 0 & 0 & 0 & 0 & 9 \\
\hline Culex gelidus (Theobald) & 398 & 100 & 0 & 0 & 0 & 0 & 0 & 0 & 498 \\
\hline Culex hilli (Edwards) & 65 & 59 & 0 & 0 & 0 & 0 & 0 & 0 & 124 \\
\hline Culex pullus (Theobald) & 0 & 2 & 0 & 0 & 0 & 0 & 0 & 0 & 2 \\
\hline Culex sitiens (Weidemann) & 2445 & 1609 & 0 & 0 & 0 & 0 & 0 & 0 & 4054 \\
\hline Lutzia halifaxii (Theobald) & 8 & 8 & 0 & 0 & 0 & 0 & 0 & 0 & 16 \\
\hline $\begin{array}{l}\text { Mansonia septempunctata } \\
\text { (Theobald) }\end{array}$ & 146 & 37 & 0 & 0 & 0 & 0 & 0 & 0 & 183 \\
\hline Mansonia uniformis (Theobald) & 403 & 54 & 0 & 0 & 0 & 0 & 0 & 0 & 457 \\
\hline $\begin{array}{l}\text { Tripteroides magnesianus } \\
\text { (Theobald) }\end{array}$ & 62 & 7 & 0 & 0 & 0 & 0 & 1 & 0 & 70 \\
\hline $\begin{array}{l}\text { Uranotaenia albescens } \\
\text { (Theobald) }\end{array}$ & 0 & 0 & 0 & 0 & 0 & 0 & 1 & 0 & 1 \\
\hline Verrallina carmenti (Taylor) & 1747 & 551 & 0 & 2 & 0 & 0 & 0 & 0 & 2300 \\
\hline Verrallina funerea (Theobald) & 3177 & 983 & 23 & 3 & 4 & 1 & 5 & 0 & 4196 \\
\hline Verrallina lineata (Taylor) & 551 & 166 & 0 & 2 & 0 & 0 & 0 & 1 & 720 \\
\hline Total & 29,874 & 14,665 & 814 & 358 & 15 & 5 & 11 & 2 & 45,744 \\
\hline
\end{tabular}

Ground level: within $1 \mathrm{~m}$ of the ground $(<1 \mathrm{~m})$; sub-canopy level: $6 \mathrm{~m}$ above the ground $(\geq 6 \mathrm{~m})$

Table 3 The total abundance and species richness of identified female mosquitoes captured, by trap types and height

\begin{tabular}{|c|c|c|c|c|c|c|}
\hline \multirow[t]{3}{*}{ Trap types ${ }^{a}$} & \multicolumn{3}{|c|}{ Abundance of species ${ }^{b}$} & \multicolumn{3}{|c|}{ Species richness ${ }^{b}$} \\
\hline & \multicolumn{2}{|l|}{ Height } & \multirow[t]{2}{*}{ Grand total } & \multicolumn{2}{|l|}{ Height } & \multirow[t]{2}{*}{ Grand total } \\
\hline & Ground level & Sub-canopy level & & Ground level & Sub-canopy level & \\
\hline$S$ & 11 & 2 & 13 & 5 & 2 & 7 \\
\hline $\mathrm{SO}$ & 15 & 5 & 20 & 5 & 5 & 7 \\
\hline SOD & 814 & 358 & 1172 & 8 & 8 & 11 \\
\hline POD & 29,874 & 14,665 & 44,539 & 23 & 23 & 26 \\
\hline Grand total & 30,714 & 15,030 & 45,744 & 24 & 24 & 27 \\
\hline
\end{tabular}

a POD, Passive box trap with octenol and dry ice; S, sticky net trap without any lure; SO, sticky net trap with octenol; SOD, sticky net trap with octenol and dry ice

${ }^{b}$ Abundance is the number of specimens collected; richness is the number of different species collected 
Table 4 Influence of trap and height on mosquito relative abundance and species richness

\begin{tabular}{|c|c|c|c|c|c|c|}
\hline \multirow[t]{2}{*}{ Factors } & \multicolumn{3}{|c|}{ Abundance } & \multicolumn{3}{|c|}{ Species richness } \\
\hline & $x^{2}$ & $d f$ & $P$ value & $x^{2}$ & $d f$ & $P$ value \\
\hline Trap type & 1400.02 & 3 & $<0.001$ & 974.85 & 3 & $<0.001$ \\
\hline Height & 23.62 & 1 & $<0.001$ & 1.58 & 1 & 0.209 \\
\hline Trap type $\times$ Height & 1.45 & 3 & 0.694 & 5.89 & 3 & 0.117 \\
\hline
\end{tabular}

Two separate generalised linear models with negative binomial distributions were used to estimate the influence of experimental factors for both mosquito abundance $\left(R^{2}=0.922\right)$ and species richness $\left(R^{2}=0.921\right)$

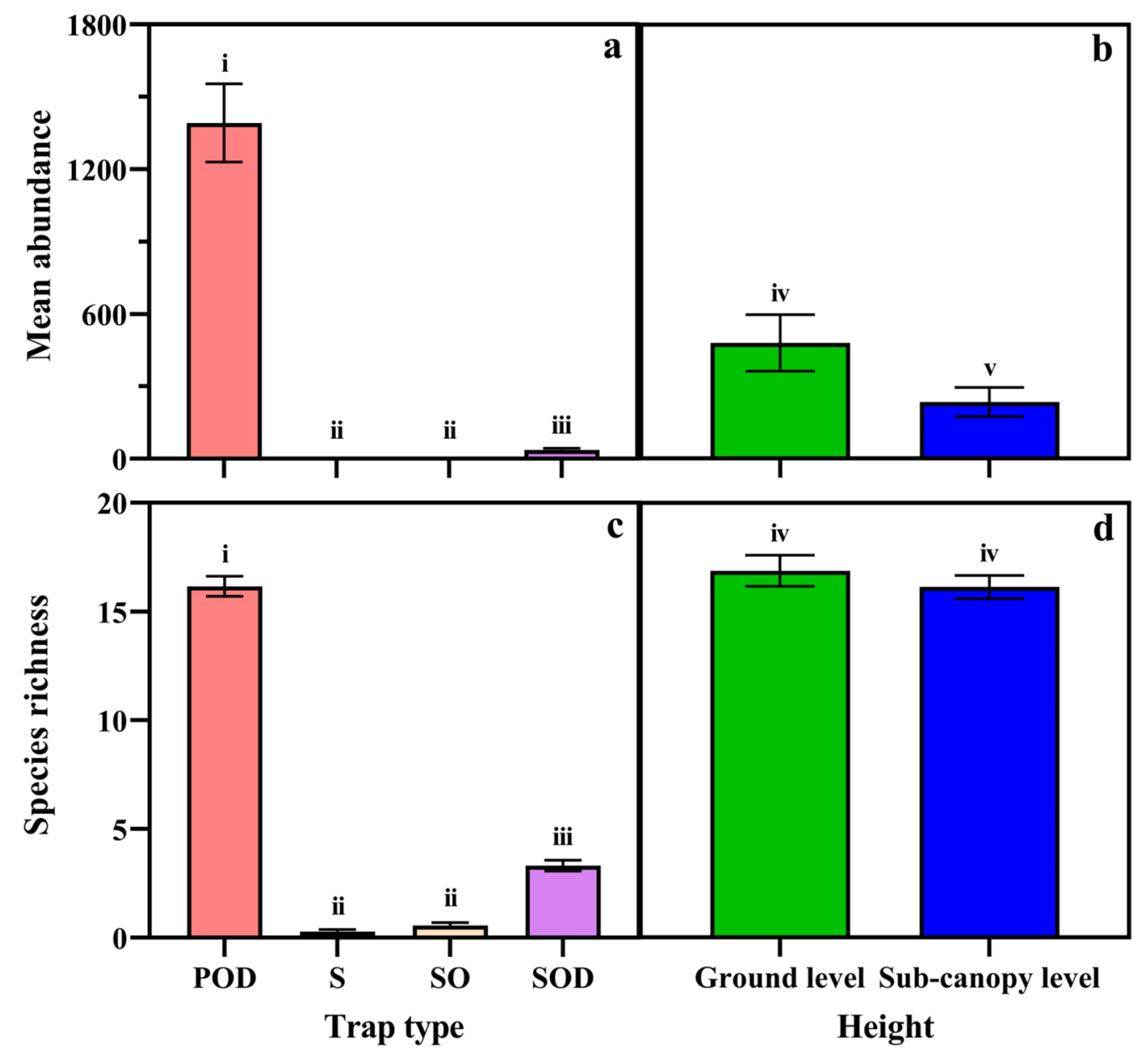

Fig. 3 The mean nightly/daily abundance and species richness of mosquitoes captured by different trap types at two heights (ground level and . a Mosquito abundance by trap type, $\mathbf{b}$ mosquito abundance by height, $\mathbf{c}$ species richness by trap type, $\mathbf{d}$ species richness by height. Note: Data are presented as the means \pm standard deviation (SD) per night. Abbreviations: POD, Passive box trap with octenol and dry ice; S, sticky net trap without any lure; SO, sticky net trap with octenol; SOD, sticky net trap with octenol and dry ice

sticky net trap with octenol $(0.63 \pm 0.15)$ or the sticky net trap without any lure $(0.4 \pm 0.1)$ (Fig. 3a).

The average ( \pm standard deviation) mosquito abundance per trap-night was significantly influenced by trap height (GLM, $P<0.001$; Table 4 , Fig. $3 \mathrm{~b}$ ) with more mosquitoes captured at ground level $(479.8 \pm 116.9)$ than in the sub-canopy $(234.8 \pm 60.4)$. There was no significant interaction (GLM, $P=0.694$ ) between trap type and height.

Mosquito species richness was significantly influenced by trap type (GLM, $P<0.001$; Table 4 ; Fig. 3c). PODs caught significantly $(16.2 \pm 0.5)$ more species than any of 
the sticky net traps. Among sticky net trap types, a significantly greater richness was captured using octenol and dry ice $(3.3 \pm 0.3)$ than either the sticky net trap with octenol $(0.6 \pm 0.1)$ or the sticky net trap without any lure $(0.3 \pm 0.1)$.

Mosquito species richness was not significantly influenced by trap height (GLM, $P=0.209$; Table 4; Fig. 3d). The mean of daily species richness estimated from all four trap types over the 16 days at ground level $(17.1 \pm 2.8)$ was not significantly different to that in the sub-canopy (16.2 \pm 2.1$)$. Lastly, species richness was not significantly influenced (GLM, $P=0.117$ ) by an interaction between trap type and height.

The mosquito species richness increased with increases in the number of sampling nights (Fig. 4). After 1 night of sampling, traps collected about $70 \%$ of the cumulative number of species collected over 16 nights of sampling (POD: $19 \pm 2.37$; SOD: $4.36 \pm 1.34$; SO: $1.2 \pm 0.83$; S: $0.71 \pm 0.83)$.

\section{Mosquito assemblage composition}

Variations in mosquito assemblage composition were positively correlated with trap types (manyglm function, LRT $=2276.6, P=0.001)$, with height at which traps were deployed (manyglm, LRT $=194, P=0.001$ ) and across trap types and height (manyglm, LRT $=48.7, P=0.001$ ). The mean abundance of mosquito species (for the 22 species for which $>5$ specimens were sampled) was significantly influenced by trap type $(P=0.001$; Table 2$)$. Additionally, mean abundances of seven mosquito species were significantly influenced by trap height (Table 5), with the mean abundances of Ae. vigilax (manyglm, $P=0.001$ ), An. farauti (manyglm, $P=0.001$ ), Mansonia uniformis (manyglm, $P=0.007$ ), Tripteroides magnesianus (manyglm, $P=0.001$ ) and Ve. funerea (manyglm, $P=0.001$ ) being significantly greater in traps at ground level (Table 2; Fig. 4), and the mean abundances of Coquillettidia sp. near crassipes (manyglm, $P=0.002$ ) and Coquillettidia xanthogaster (manyglm, $P=0.033$ ) being significantly greater in traps within the sub-canopy (Table 5; Fig. 5).

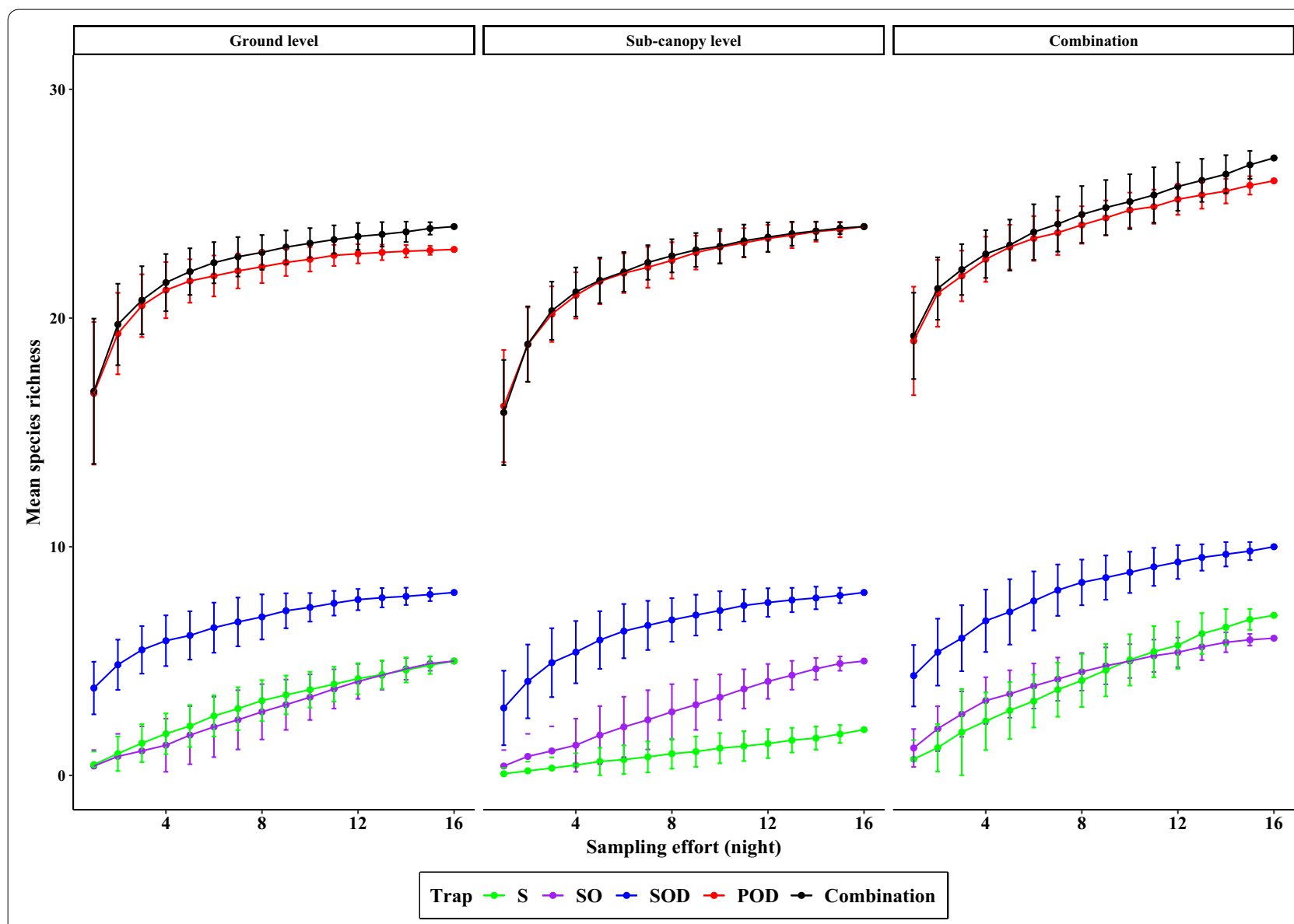

Fig. 4 Cumulative mean species richness of mosquitoes by trap types and height per sampling effort (night) in Cattana Wetlands, Cairns, Australia. Note: data are presented as nightly cumulative means \pm SD 
Table 5 Seven mosquito species whose abundances were influenced by trap and height

\begin{tabular}{|c|c|c|c|c|}
\hline \multirow[t]{2}{*}{ Mosquito species } & \multicolumn{2}{|c|}{ Trap type } & \multicolumn{2}{|l|}{ Height } \\
\hline & LRT & $P$ value & LRT & $P$ value \\
\hline Aedes vigilax (Skuse) & 193.349 & 0.001 & 21.173 & 0.001 \\
\hline Anopheles farauti (Laveran) & 157.601 & 0.001 & 45.604 & 0.001 \\
\hline $\begin{array}{l}\text { Coquillettidia sp. near crassipes } \\
\text { (Marks) }\end{array}$ & 128.046 & 0.001 & 17.098 & 0.002 \\
\hline Coquillettidia xanthogaster (Edwards) & 78.166 & 0.001 & 10.112 & 0.033 \\
\hline Mansonia uniformis (Theobald) & 98.73 & 0.001 & 13.026 & 0.007 \\
\hline Tripteroides magnesianus (Theobald) & 66.933 & 0.001 & 24.343 & 0.001 \\
\hline Verrallina funerea (Theobald) & 147.161 & 0.001 & 22.833 & 0.001 \\
\hline
\end{tabular}

The likelihood tests (LRTs) were used to estimate the interaction between mosquito species with trap type and height

A large separation between the structure of mosquito assemblages sampled by the passive and sticky net traps was seen (Fig. 6), with the assemblage captured by the POD separating into two groups by trap height. There was substantial overlap among the assemblages sampled by the sticky net trap versions. However, the assemblage captured with the SOD had a greater species richness and abundance compared to the other sticky net traps, shown as a separation between these groups in the ordination in Fig. 6.

\section{Discussion}

This study compared the effectiveness of different traps for sampling mosquitoes and quantified the effect of trap height on mosquito assemblages. Defining trap effectiveness by the number of species captured and the abundance of each species, our results show that that the POD was significantly more effective than any of the sticky net traps. Aedes, Anopheles and Verrallina were the dominant mosquito genera sampled by each trap. However, while Culex were very abundantly sampled in PODs, very few were collected in sticky net traps, regardless of the lures used, suggesting that sticky net traps were less effective for sampling Culex. Despite its overall low sampling efficiency, the sticky net trap did capture one species, Ur. albescens, that the POD did not. Furthermore, the sticky net trap may provide information about natural flight patterns than the POD cannot as sticky traps capture mosquitoes from two horizontal directions [21].

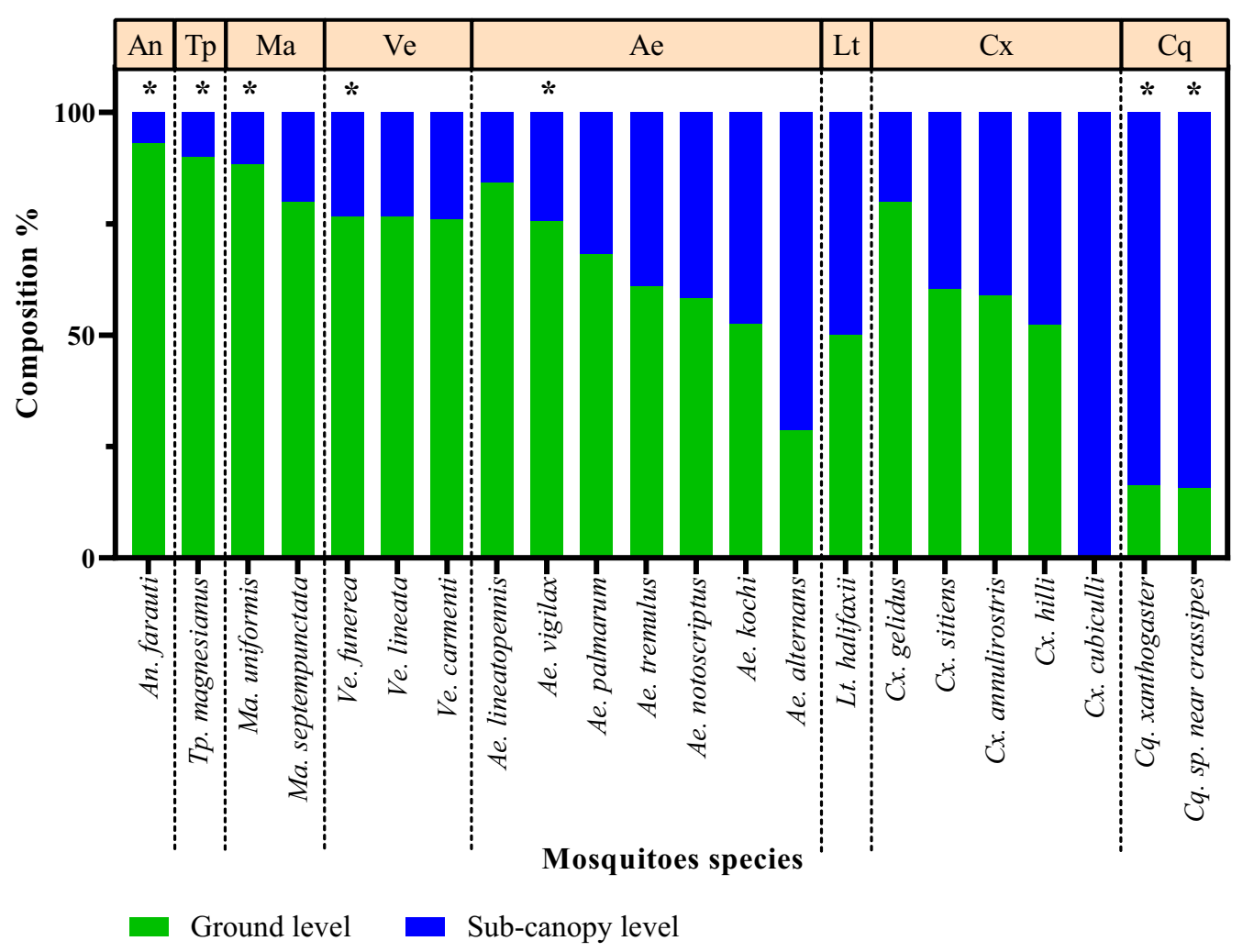

Fig. 5 Relative composition of the 22 most abundantly sampled mosquito species by height in Cattana Wetlands, Cairns, Australia. Species whose abundance was significantly influenced by height are denoted with an asterisk. The graph excludes 5 mosquito species because the total number of each species captured was < 5. Abbreviations: An., Anopheles; Ma., Mansonia; Ve., Verralina; Ae., Aedes; Lt., Lutzia; Cx., Culex; Cq., Coquillettidia 


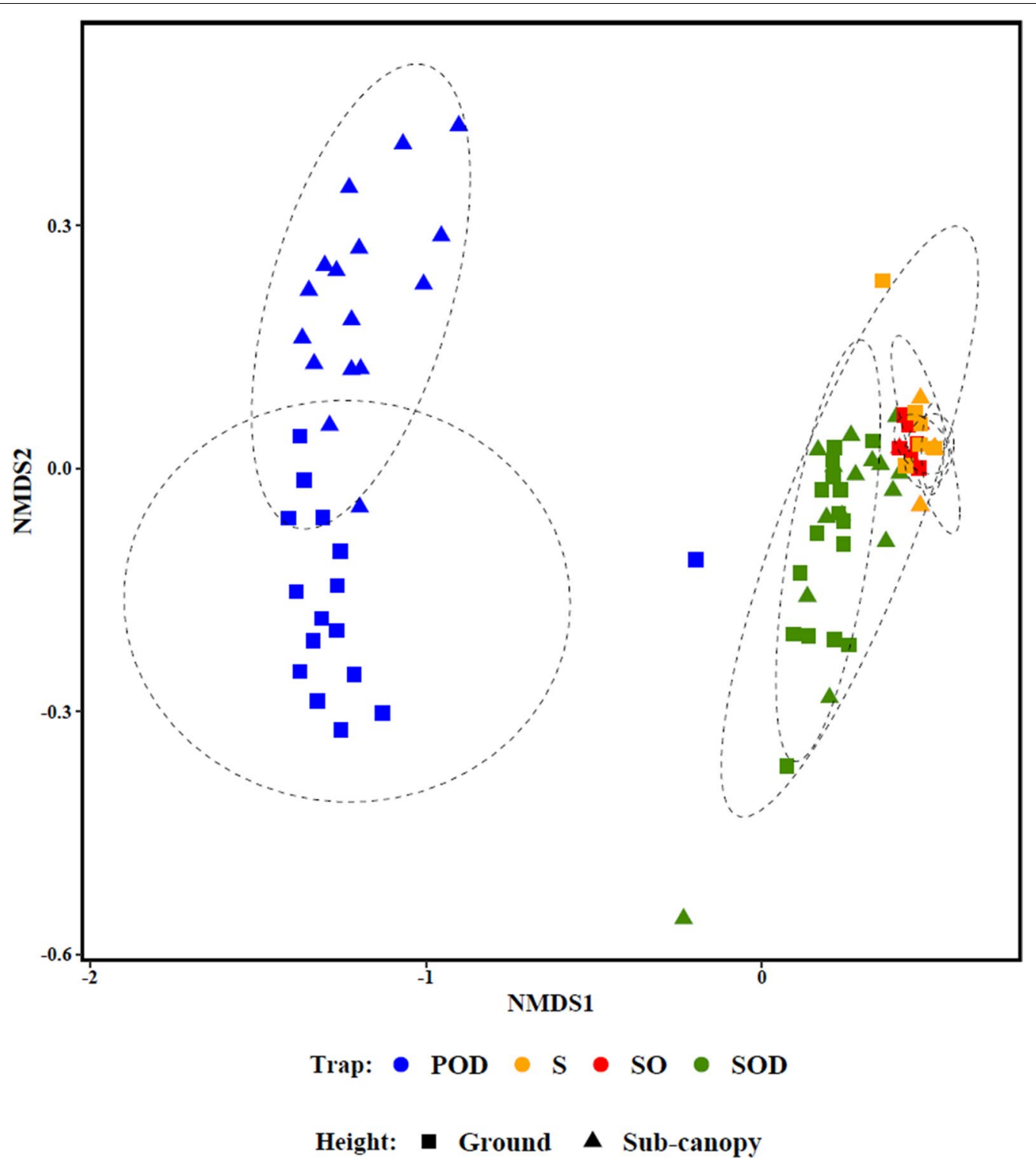

Fig. 6 nMDS of mosquito species composition from replicated trapping efforts comparing different trap types and heights. Abbreviations: nMDS, Non-metric multidimensional scaling

Therefore, a combination of field sampling methods over multiple days was required to more comprehensively and representatively sample mosquito populations and thereby better describe the mosquito assemblage in an area $[21,23]$.

The abundance and composition of mosquito assemblages sampled clearly depended on whether traps were placed near the ground or in the sub-canopy. This is supported by previous investigations in Australia [35], The Gambia [11], Madagascar [13], Malaysia [20], Mali [14] and the USA [18]. In this study, the abundance of mosquitoes sampled at ground level was more than twofold greater than the abundance sampled in the sub-canopy. However, the richness of mosquito species was similar at both heights. Variations in abundance of mosquito species at different heights may be influenced by the structure of the vegetation the provides sugar sources [36-38], resting sites, oviposition sites or preferred blood meal hosts $[39,40]$. In this study, Ae. vigilax and Ve. funerea were collected in significantly greater numbers at the ground level. The larvae of both of these mosquito species are found in saline and brackish water [41]. Cattana Wetlands has a number of fresh and brackish water anthropogenic lakes which may serve as larval habitats 
for these species and thus explain their abundance at the ground level [42, 43].

Mosquitoes with feeding preferences for large mammals are hypothesised to be predominantly found near the ground, whereas ornithophilic species may predominantly be in the sub-canopy or the canopy layer $[35,44]$. For example, the ornithophilic Culex pipiens complex were found most frequently in the sub-canopy level where their preferred blood meal hosts are generally found $[17,18,45]$. In this study, most $C q$. sp. near crassipes and Cq. xanthogaster were collected in the sub-canopy but a few were sampled at ground level, consistent with both their known ornithophilic blood-feeding habits and their preference for oviposition in freshwater wetlands with aquatic plants [32, 42]. Unsurprisingly, 94\% of An. farauti were sampled in traps at ground level, which is consistent with their known preference for blood meals on large animals $[46,47]$. While Ae. vigilax is known as a generalist feeder [41], this mosquito's role as a vector of dog heartworm (Dirofilaria immitis) suggests a preference for biting large mammals, including dogs [32, 48]. In addition, an investigation of the host preferences of $M a$. uniformis at Kowanyama, Australia in 1979 found that 15 out 17 blood-fed mosquitoes captured were positive for large mammals, including human, cow, pig, horse and marsupial $[49,50]$. Moreover, $C x$. annulirostris and $C x$. sitiens were collected at both the ground and sub-canopy levels, consistent with their generalist feeding behaviours $[51,52]$.

\section{Conclusion}

The POD clearly outperformed all three sticky net trap variants in both numbers and abundance of species sampled in this wetland. These results contribute new insights into mosquito communities within an Australian wetland habitat. Despite mosquitoes being overall significantly more abundant at the ground level, two species were caught in higher abundances in traps set in the subcanopy level, with species richness comparable at ground and sub-canopy levels. This suggests that while most species more frequently inhabit lower heights in this habitat, many mosquito species also freely fly to heights of $6 \mathrm{~m}$ albeit in lower abundances. Potentially, variations in mosquito species distributions between these two heights are influenced by their preferred hosts' availability, the vegetation structure, resting and larval habitats and environmental factors.

\section{Abbreviations}

Ae:: Aedes; An.: Anopheles; $\mathrm{CO}_{2}$ : Carbon dioxide; Cq.: Coquillettidia; Cx.: Culex; GLM: Generalised linear model; HLC: Human landing catch; LRT: Likelihood ratio; Lt:: Lutzia; Ma:: Mansonia; NMDS: Non-metric multidimensional scaling;
POD: Passive box trap with octenol and dry ice; S: Sticky trap without any lure; SO: Sticky trap with octanol; SOD: Sticky trap with octenol and dry ice; Tp.: Tripteroides; Ur:: Uranotaenia; Ve.: Verralina.

\section{Acknowledgements}

We are grateful to the Cairns Regional Council for permission to work in the Cattana Wetlands. Personally, I also thank Dr Michael I Bangs for his extraordinary support in encouraging me to continue studying at the postgraduate level and to learn more about mosquito-borne diseases.

\section{Authors' contributions}

BFS, TLR, TL and TRB conceived and designed the study and critically revised the manuscript. BFS performed the field and laboratory studies, analysed the data and drafted the manuscript. TLR and KMS helped in data analysis and manuscript revision. MT and CP helped in study implementation. All authors read and approved the final manuscript.

\section{Funding}

The work was supported by an Australia Award Scholarships (AAS) to BS.

\section{Availability of data and materials}

The datasets supporting the conclusions of this article are available at Research Data JCU repository: https://research.jcu.edu.au/data/default/rdmp/ home.

\section{Declarations}

Ethics approval and consent to participate

Not applicable.

\section{Consent for publication}

Not applicable.

\section{Competing interests}

The authors declare that they have no competing interests.

\section{Author details}

${ }^{1}$ Australian Institute of Tropical Health and Medicine (AITHM), James Cook University, Cairns, QLD 4878, Australia. ${ }^{2}$ Laboratory of Malaria and Vector Research, National Institute of Allergy and Infectious Diseases (NIAH), National Institutes of Health (NIH), Rockville, MD, USA.

Received: 4 May 2021 Accepted: 8 September 2021

Published online: 07 October 2021

\section{References}

1. World Health Organization. Global vector control response 2017-2030; 2017. Geneva:World Health Organization. https://apps.who.int/iris/ handle/10665/259205. Accessed 13 July 2020.

2. Sinka ME, Pironon S, Massey NC, Longbottom J, Hemingway J, Moyes CL, et al. A new malaria vector in Africa: predicting the expansion range of Anopheles stephensi and identifying the urban populations at risk. Proc Natl Acad Sci USA. 2020;117:24900-8.

3. Taylor B. Changes in the feeding behaviour of a malaria vector Anopheles farauti Lav., following the use of DDT as a residual spray in houses in the British Solomon Islands Protectorate. Trans R Entomol Soc Lond. 1975; 127:277-92.

4. Russell TL, Beebe NW, Cooper RD, Lobo NF, Burkot TR. Successful malaria elimination strategies require interventions that target changing vector behaviours. Malar J. 2013;12:56.

5. Bhatt S, Weiss DJ, Cameron E, Bisanzio D, Mappin B, Dalrymple U, et al. The effect of malaria control on Plasmodium falciparum in Africa between 2000 and 2015. Nature. 2015;526:207-11.

6. Beebe N, Russell T, Burkot T, Lobo N, Cooper R. The systematics and bionomics of malaria vectors in the southwest Pacific. In: Manguin S, editor. Anopheles mosquitoes-new insights into malaria vectors. New York: InTech; 2013. p. 357-94. 
7. Elyazar IR, Sinka ME, Gething PW, Tarmidzi SN, Surya A, Kusriastuti R, et al. The distribution and bionomics of Anopheles malaria vector mosquitoes in Indonesia. In: Rollinson D, editor., et al., Advances in parasitology, vol. 115. Cambridge: Academic Press; 2013. p. 173-266.

8. World Health Organization. Guidelines for malaria vector control; 2019. Geneva: World Health Organization. https://apps.who.int/iris/handle/ 10665/310862. Accessed 13 July 2020.

9. Sedda L, Lucas ER, Djogbénou LS, Edi AVC, Egyir-Yawson A, Kabula $\mathrm{Bl}$, et al. Improved spatial ecological sampling using open data and standardization: an example from malaria mosquito surveillance. J R Soc Interface. 2019;16:20180941.

10. Farlow R, Russell TL, Burkot TR. Nextgen vector surveillance tools: sensitive, specific, cost-effective and epidemiologically relevant. Malar J. 2020;19:432.

11. Gillies MT, Wilkes TJ. The vertical distribution of some West African mosquitoes (Diptera, Culicidae) over open farmland in a freshwater area of the Gambia. Bull Entomol Res. 1976;66:5-15.

12. Liew C, Curtis CF. Horizontal and vertical dispersal of dengue vector mosquitoes, Aedes aegypti and Aedes albopictus, in Singapore. Med Vet Entomol. 2004;18:351-60.

13. Tantely LM, Randrianambinintsoa FJ, Woog F, Raharinirina MR, Ratsimbazafy J, Boyer S, et al. Horizontal and vertical distribution of mosquitoes (Diptera: Culicidae) in the rainforest of Maromizaha, Madagascar: implications for pathogen transmission to humans and animals. Austral Entomol. 2019;58:897-906.

14. Huestis DL, Dao A, Diallo M, Sanogo ZL, Samake D, Yaro AS, et al. Windborne long-distance migration of malaria mosquitoes in the Sahel. Nature. 2019;574:404-8.

15. Bidlingmayer WL. Mosquito flight paths in relation to the environment. 1. Illumination levels, orientation, and resting areas. Ann Entomol Soc Am. 1971;64:1121-31.

16. Bidlingmayer $W L$, Hem DG. The range of visual attraction and the effect of competitive visual attractants upon mosquito (Diptera: Culicidae) flight. Bull Entomol Res. 1980;70:321-42.

17. Chathuranga WGD, Karunaratne S, Fernando BR, De Silva W. Diversity, distribution, abundance, and feeding pattern of tropical ornithophilic mosquitoes. J Vector Ecol. 2018;43:158-67.

18. Darbro JM, Harrington LC. Bird-baited traps for surveillance of West Nile mosquito vectors: effect of bird species, trap height, and mosquito escape rates. J Med Entomol. 2006;43:83-92.

19. Groves CP. Biogeographic region. Chicago: Encyclopedia Britannica; 2017.

20. Brant HL, Ewers RM, Vythilingam I, Drakeley C, Benedick S, Mumford JD. Vertical stratification of adult mosquitoes (Diptera: Culicidae) within a tropical rainforest in Sabah, Malaysia. Malar J. 2016;15:370.

21. Silver JB. Mosquito ecology: field sampling methods. 3rd ed. New York: Springer; 2008.

22. Southwood TRE, Henderson PA. Ecological methods. 3rd ed. Oxford: Blackwell Science Ltd; 2009.

23. Service MW. A critical review of procedures for sampling populations of adult mosquitoes. Bull Entomol Res. 1977;67:343-82.

24. Service MW. Mosquito ecology: field sampling methods. 2nd ed. London and New York: Elsevier Applied Science; 1993.

25. Burkot TR, Russell TL, Reimer $\amalg$, Bugoro H, Beebe NW, Cooper RD, et al. Barrier screens: a method to sample blood-fed and host-seeking exophilic mosquitoes. Malar J. 2013:12:49.

26. Pollard EJM, Russell TL, Burkot TR. Maximising mosquito collections from barrier screens: the impacts of physical design and operation parameters. Parasit Vectors. 2019;12:31.

27. Todd S. Cattana wetlands vegetation management plan. Cairns: Natural Resource Assessments Pty Ltd; 2016.

28. Gallery RE. Ecology of tropical rain forests. In: Monson RK, editor. Ecology and the environment. New York: Springer; 2014. p. 247-72.

29. Ritchie SA, Cortis G, Paton C, Townsend M, Shroyer D, Zborowski P, et al. A simple non-powered passive trap for the collection of mosquitoes for arbovirus surveillance. J Med Entomol. 2013;50:185-94.

30. Meyer DB, Johnson BJ, Fall K, Buhagiar TS, Townsend M, Ritchie SA. Development, optimization, and field evaluation of the novel collapsible passive trap for collection of mosquitoes. J Med Entomol. 2018;55:706-10.

31. Cochran WG, Cox GM. Experimental designs. 2nd ed. Oxford:Wiley; 1957.
32. Ehlers G, Alsemgeest D. Mosquito control association of Australia, mosquito control association of Australia North Queensland division. In: Elhersm G, Alsemgeest D, editors. Common mosquitoes of North Queensland: identification and biology of adult mosquitoes. 1st ed. Queensland: Mosquito Control Association of Australia Inc; 2011.

33. Oksanen J, Blanchet FG, Friendly M, Kindt R, Legendre P, McGlinn D, et al. Vegan: community ecology package. R package version 2.5-7; 2019. https://CRAN.R-project.org/package=vegan. Accessed 10 Dec 2020.

34. Wang Y, Naumann U, Wright ST, Warton DI. Mvabund —an R package for model-based analysis of multivariate abundance data. Methods Ecol Evol. 2012;3:471-4.

35. Jansen CC, Zborowski P, Ritchie SA, Van Den Hurk AF. Efficacy of birdbaited traps placed at different heights for collecting ornithophilic mosquitoes in eastern Queensland, Australia. Aust J Entomol. 2009:48:53-9.

36. Martinez-Ibarra JA, Rodriguez MH, Arredondo-Jimenez JI, Yuval B. Influence of plant abundance on nectar feeding by Aedes aegypti (Diptera: (ulicidae) in southern Mexico. J Med Entomol. 1997;34:589-93.

37. Stone CM, Jackson BT, Foster WA. Effects of bed net use, female size, and plant abundance on the first meal choice (blood vs sugar) of the malaria mosquito Anopheles gambiae. Malar J. 2012;11:3.

38. Andrews ES, Schoeler GB, Gozalo AS, Carbajal F, Lopez-Sifuentes V, Turell MJ. Species diversity, seasonal, and spatial distribution of mosquitoes (Diptera: Culicidae) captured in aotus monkey-baited traps in a forested site near lquitos. Peru J Med Entomol. 2014;51:1127-35.

39. Clements AN. The biology of mosquitoes: sensory reception and behaviour, vol. 2. Wallingford: CABI Publishing; 1999.

40. Derraik JG, Snell AE, Slaney D. Vertical distribution of adult mosquitoes in native forest in Auckland, New Zealand. J Vector Ecol. 2005;30:334-6.

41. Lee DJ, Hicks MM, Griffiths M, Russell RC, Marks EN. The Culicidae of the Australasian region, vol. 3. Canberra: Australian Government Publishing Service; 1984

42. Webb C, Doggett S, Russell R. A guide to mosquitoes of Australia. Clayton: CSIRO Publishing; 2016

43. Webb CE, Russell RC. Dispersal of the Mosquito Aedes vigilax (Diptera: Culicidae) From Urban Estuarine Wetlands in Sydney. Australia J Med Entomol. 2019;56:1290-5.

44. Swanson DA, Adler PH, Malmqvist B. Spatial stratification of hostseeking Diptera in boreal forests of Northern Europe. Med Vet Entomol. 2012;26:56-62.

45. Service MW. Flight periodicities and vertical distribution of Aedes cantons (Mg.), Ae. geniculatus (Ol.), Anopheles plumbeus Steph. and Culex pipiens L. (Dipt., Culicidae) in southern England. Bull Entomol Res. 1971;60:639-51.

46. Russell TL, Beebe NW, Bugoro H, Apairamo A, Cooper RD, Collins FH, et al. Determinants of host feeding success by Anopheles farauti. Malar J. 2016;15:152.

47. Burkot TR, Graves PM, Paru R, Lagog M. Mixed blood feeding by the malaria vectors in the Anopheles punctulatus complex (Diptera: Culicidae). J Med Entomol. 1988;25:205-13.

48. Smout FA, Skerratt LF, Butler JR, Johnson CN, Congdon BC. Dingoes (Canis dingo Meyer, 1793) continue to be an important reservoir host of Dirofilaria immitis in low density housing areas in Australia. Vet Parasitol. 2016;215:6-10.

49. Kay B, Boreham P, Williams G. Host preferences and feeding patterns of mosquitoes (Diptera: Culicidae) at Kowanyama, Cape York Peninsula, northern Queensland. Bull Entomol Res. 1979;69:441-57.

50. Lee D, Hicks MM, Debenham M, Griffiths M, Bryan J, Marks EN. The Culicidae of the Australasian region, vol. 9. Canberra: Australian Government Publishing Service; 1988.

51. Williams CR, Kokkinn MJ, Smith BP. Intraspecific variation in odor-mediated host preference of the mosquito Culex annulirostris. J Chem Ecol. 2003;29:1889-903.

52. Stephenson EB, Murphy AK, Jansen CC, Peel AJ, McCallum H. Interpreting mosquito feeding patterns in Australia through an ecological lens: an analysis of blood meal studies. Parasit Vectors. 2019;12:156.

\section{Publisher's Note}

Springer Nature remains neutral with regard to jurisdictional claims in published maps and institutional affiliations. 